\title{
Research and Application of BIM Technology in 5D Engineering Management
}

\author{
Na Xiong ${ }^{1, \text { a }}$ and Jian Tang ${ }^{2, ~ b,{ }^{*}}$ \\ ${ }^{1}$ Nanchang Institute of Technology, No 901 Hero Avenue, Changbei Economic Development Zone, \\ Nanchang, Jiangxi, China (330044) \\ ${ }^{2}$ Jiangxi Science \& Technology Normal University, No. 605, Fenglin Road, Changbei Economic \\ Development Zone, Nanchang, Jiangxi Province (330013) \\ a289610964@qq.com, b176024108@qq.com
}

\section{Keywords: Building information model ; BIM5D ; Construction management ; Cost management}

\begin{abstract}
With the construction of dynamic management is becoming more and more complex, the traditional schedule management has been unable to meet the needs of modernization, based on BIM construction simulation came into being. This paper describes the content and current situation of the construction of information management, this paper introduces the construction of dynamic resource management based on BIM5D Technology. Through the creation of 3D models, schedule information and pricing information, information integration platform for the project progress, cost, material control and other accurate information to help managers effective decision-making and fine management, management of large-scale construction projects for the project manager provide new avenues and methods.
\end{abstract}

\section{Introduction}

In the process of social information, the extensive management of the construction industry has been unable to meet the requirements of sophisticated management of complex buildings. Data managers need to handle a lot of information manually every day, and the data users - project management or technical staff rely on paper materials or personal network communication to convey project information, it is difficult to timely query and management of construction materials or real-time tracking project construction happening. At present, most enterprises, mainly for the construction unit, the lack of modern management theory, in order to reduce construction costs, the pursuit of maximum benefits, do not want to invest too much in the data management, lack of attention to data management, management system for the late completion and operation of the work of the information query inconvenience, as the future work of the hidden dangers. In the construction of information management research, and gradually to the information network management direction, for this three-dimensional visualization of information collaborative management platform will become an important channel for enterprise management.

In the aspect of construction resource management, the use of mathematical algorithms to optimize the allocation of resources, Padilla and Carr[1] developed a simulation model simulation project in the decision-making process of resource allocation in different strategies, Karaa and Nasr and Senouci and Adeli[2] proposed a mathematical method to optimize the use of resources, Moonseo Park[3] proposed based on the model to provide accurate resource usage. Domestic construction resource management relies on experience and auxiliary management software to optimize the construction period and construction resource allocation. Tianjin University, Zhang Lianying[4-5] and other genetic algorithms to find the key path of the resource optimization program, XU Hua[6] improved heuristic algorithm to solve the problem of balance optimization of dynamic alliance project management resources, Zhang Shao yang[7-8] is realized the control of resources by using resource intensity softening method based on Petri net. To sum up, the current resource management method is mainly in the two-dimensional project management software associated with the progress of the program in the resource information, the use of built-in heuristic algorithm for resource management, but in practice managers still need experience management project. Computer development and construction needs, to promote BIM technology came into 
being. Through the practice found that efficient resource management can achieve $10 \%$ to $30 \%$ of the cost savings[9], BIM technology integration of traditional management methods, through information integration platform for information management for construction resources management provides a solution.

\section{The creation of $5 \mathrm{D}$ information model}

5D information model is formed by the three-dimensional model of additional progress information and cost information integration, as shown in Figure 1. The 3D modeling software is used to create the professional model, which is connected with the progress information on the basis of the 3D model to form the 4D building information model, so as to realize the construction simulation of the component visualization and the construction schedule management. Through the import into the pricing file, the association of the $3 \mathrm{D}$ model with the list, to achieve more than the project comparison and so on. The relationship between the 3D model and the progress information and the cost information is based on the model component and the WBS decomposition as the core, so as to realize the progress management, cost management and resource management of the construction project and so on. As shown in Fig. 1.

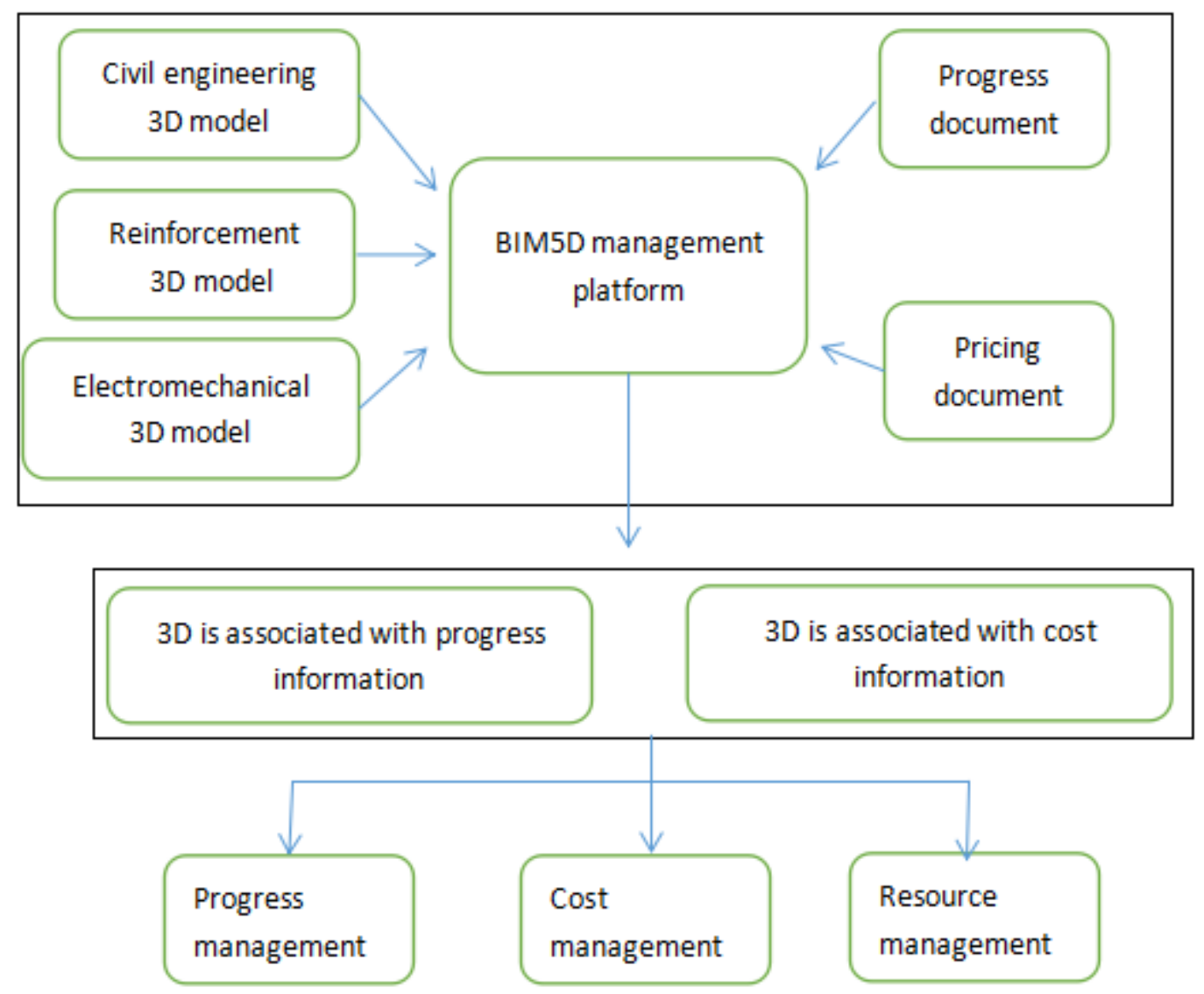

Fig. 1 BIM5D information integration process

\section{Analysis and Application of BIM5D in Practical Engineering}

In this paper, a large-scale comprehensive construction projects in Tianjin as a project case. The project construction area of $95697 \mathrm{~m} 2$, of which the ground floor area of $62160 \mathrm{~m} 2$, underground construction area of $33537 \mathrm{~m} 2$. Project focus and difficulties: large-scale building, floor-intensive, underground construction and floor number covers the entire site, the venue is small, to the construction organization and the scene layout to bring greater difficulties; the underground structure of the project is three floors, covers an area of large, the depth of the pit - 13. 95m, 
earthwork, how to organize soil excavation, to ensure smooth off-site traffic and environmental cleanliness is also the construction of the key issues to be aware of; basement facilities and equipment, many lines, to the design and construction of the difficulty. The project can use the BIM5D software platform to implement the direct import of the GCL format model and have the IFC format universal interface. The model established by Revit and other software can be converted into IFC format and imported into BIM5D to form a complete BIM application model, complete the association of the model with the schedule document (project format), the association with the contract, the list, the quota information, and the construction drawing. With this software. we can also click on the component in the model to see the type of material, material, volume and other attributes of the image, effectively assist the construction management decision-making, in order to achieve fine management, saving construction costs and improve construction quality.

The use of glodon BIM5D recorded in the completion of the situation, on-site visa situation, business people can quickly complete the calculation of the finished part of the project, the rapid completion of the progress of the party to apply for the amount of sub-contract and the amount of software, (Income - expenditure) and section (budget - expenditure), the profit and loss analysis is carried out on a regular basis from time to time to help the company understand the project capital situation, and the profit and loss of the project, strengthening the cost management of the project.

Technical personnel in accordance with the flow of water divided into the management of the water flow, the model can be divided into management of the face, and the progress of the plan, subcontract, Party list, drawings and other information in accordance with the work surface organization and management. In this way, you can clearly see the progress of each flow of time, the amount of steel works, the amount of components, drawings, inventory of the amount of work, the required amount of material, fixed labor force, to help production management staff reasonable arrangements for production plans, Conflict of work [10], to ensure the progress of the project, saving the cost of the project.

In the construction site, found the quality and safety issues, through the phone on the quality and safety of content to take pictures, recording and writing, and associated model. At the same time, to assist the production staff to manage the quality and safety, reduce the construction risk, to ensure the quality and safety of the project.

\section{Conclusions}

From the perspective of project management, from $3 \mathrm{D}, 4 \mathrm{D}$ to $5 \mathrm{D}$ to $\mathrm{nD}$ integrated management is the core of future BIM development, for BIM-based 5D technology research, have a higher value, to solve the construction and management of many problems. The development of the construction industry is important. Project management should pay more attention to the practical experience and engineering data of similar projects in the past, and combine with the new project's schedule, cost control and resource optimization to achieve comprehensive project management, not just the progress simulation cost tracking. With BIM technology continues to mature, will establish a series of relational database, it can quickly and accurately to enhance the accuracy and efficiency of the construction budget, BIM get through the whole chain of life in the construction field.

\section{References}

[1] E. Padilla, R. Carr: Resource strategies for dynamic project management, Journal of construction engineering and management [J]. (1991), 117(2) : 2779-2793.

[2] F. Karaa, A. Nasr: Resource management in construction, in: Journal of construction engineering and management. (1986), 112(1) : 28-34.

[3] Moonseo Park: Model-based dynamic resource management for construction projects. Automation in Construction [J]. (2005), 14(5) : 585-598.

[4] G. Luo, E. L. Liu and J. Wang: Resource Planning Optimization in Network Schedule Using Genetic Algorithms [J]. Journal of Tianjin University, (2004), 37(2): 179-183. (In Chinese)

[5] L. Y. Zhang, J. P. Zhang and L. Wang: Genetic Algorithms Based on MATLAB of Construction 
Project Resource Leveling [J]. Journal of Management Engineering. (2004), 18(1): 52-55. (In Chinese)

[6] H. Xu: Research of the Resource Optimization Algorithm of Virtual Enterprise Project Management [J]. Journal of inner Mongolia normal university, (2005). 34(3): 302-305. (In Chinese)

[7] S. Y. Zhang, X. C. Wang: Bottle-neck Identification of Resources in Highway Construction and Its Elimination Methods Based on Petri Nets [J]. Journal of Chang'an University: Natural Science Edition, (2006), 26(1): 38-42. (In Chinese)

[8] S. Y. Zhang: Study on Project Scheduling and Resource Optimization in Highway Construction Based on Petri Nets [J]. Journal of Chang'an University: Natural Science Edition, (2007), 27(4): 33-36. (In Chinese)

[9] International Alliance for Interoperability (IAI), Available from: http: / / www. iaiinternational. org / 2010.

[10]Y. H. Zhao, Y. T. Wang: Application of BIM5D in Tianjin Yongli Building Project [J]. Urban Residence, (2014) (8): 42-46. (In Chinese) 